\title{
Dyeing studies and fastness properties of brown naphtoquinone colorant extracted from Juglans regia $L$ on natural protein fiber using different metal salt mordants
}

\author{
Mohd Nadeem Bukhari ${ }^{1}$, Shahid-ul-Islam', Mohd Shabbir ${ }^{1}$, Luqman Jameel Rather ${ }^{1}$, Mohd Shahid ${ }^{1}$, Urvashi Singh ${ }^{1}$,
} Mohd Ali Khan ${ }^{2}$ and Faqeer Mohammad ${ }^{1 *}$

\begin{abstract}
In this study, wool fibers are dyed with a natural colorant extracted from walnut bark in presence and absence of mordants. The effect of aluminum sulfate, ferrous sulfate, and stannous chloride mordants on colorimetric and fastness properties of wool fibers was investigated. Juglone was identified as the main coloring component in walnut bark extract by UV visible and FTIR spectroscopic techniques. The results showed that pretreatment with metallic mordants substantially improved the colorimetric and fastness properties of wool fibers dyed with walnut bark extract. Ferrous sulfate and stannous chloride mordanted wool fibers shows best results than potassium aluminum sulfate mordanted and unmordanted wool fibers. This is ascribed due to strong chelating power of ferrous sulfate and stannous chloride mordants.
\end{abstract}

Keywords: Juglans regia L., Napthoquinone, Dyeing, Wool, Fastness properties

\section{Background}

Synthetic colorants in view of cheaper price, wide range of colors, and considerable improved fastness properties are extensively used in textile industries for dyeing of different textile materials (El-Nagar et al. 2005; Islam and Mohammad 2014). However, recent research have shown that some of the azo and benzidine based synthetic dyes produces some toxic, allergic, and carcinogenic secondary degradation byproducts (aromatic amines). In response to that, many European countries have imposed ban on their use (Ali et al. 2013; Jothi 2008; Bechtold et al. 2003). Enhanced environmental awareness has motivated researchers to reintroduce natural colorants from natural sources like plants (stem, bark, leaves, roots, and flowers), animals, and minerals (Samanta and Agarwal 2009; Shahid et al. 2012; Shahid et al. 2013). In addition to their biodegradability and compatibility with the environment, natural colorants have been recently discovered to exhibit other functional properties, such as antimicrobial activity

\footnotetext{
* Correspondence: faqeermohammad@rediffmail.com

${ }^{1}$ Department of Chemistry, Jamia Millia Islamia, New Delhi 110025, India Full list of author information is available at the end of the article
}

(Khan et al. 2012; Yusuf et al. 2015), insect repellent (Ali et al. 2013), fluorescence (Rather et al. 2015), UV protection (Grifoni et al. 2009; Sun and Tang 2011), and deodorizing (Lee et al. 2009). Therefore, natural colorants are among potential candidates for developing green textile dyeing process and serving as better alternatives or copartners to toxic synthetic colorants (Islam et al. 2014).

Despite their several advantages, there are some drawbacks associated with natural colorants, such as low exhaustion of dyes and poor fastness of dyed fabrics (Micheal et al. 2003). To overcome these problems attempts have been made which have mainly focused on the use of metallic salts as mordants (Khan et al. 2006). Metal salt mordants form complexes with dye molecules on one side and with the functional groups of textile substrate on the other side resulting in improved fastness properties or exhaustion as well as producing wide range of shades with the same dye molecule (Shahid et al. 2013; Cristea and Vilarem 2006). Many efforts have been undertaken all over the world and are currently underway for the identification and isolation of natural dyes from different plant species for their use in 
coloration as well as in functional finishing of textiles (Hwang et al. 1998; Lee and Kim 2004).

Juglans regia L. commonly known as walnut is one such dye bearing plant commonly found in temperate regions. It is cultivated commercially in Asia, western South America, United States, and Central and Southern Europe (Siva 2007). The parts of this tree like leaves, husk, and shell have been tested as potential dyeing materials for different textile substrates (Shaukat et al. 2009). Apart from textile dyeing, the parts of this tree are found to be medicinally very useful such as depurative, antihelmintic, laxative, and detergent, astringent and diuretic and exhibit antimicrobial activity to a greater extent due to high phenolic contents (Vankar et al. 2007). The coloring power of Juglans regia L. is attributed to the presence of napthoquinone class of natural colorants (Tsamouris et al. 2002). Out of the napthoquinone class, juglone (CI 75500) chemically 5hydroxy-1, 4-napthoquinone $\left(\mathrm{C}_{10} \mathrm{H}_{6} \mathrm{O}_{3}\right)$ shown in Fig. 1 acts as a substantive dye and imparts brown color to textile substrates (Chopra et al. 1996; Mirjalili et al. 2011; Mirjalili and Karimi 2013).

According to the literature, several studies have been reported on dyeing properties of walnut on different textile fibers. Ali et al. (2016) use the bark of walnut to study the effect of potassium aluminum sulphate mordant on dyeing properties of wool fibers. Hwang and Park (2013) focuses on the dyeing properties of silk fibers by the application of green walnut husk. Tutak and Benli (2011) used husk, leaves, and shell of walnut tree to study dyeing properties on different textile fibers. This study is the extension of work reported by Ali et al. (2016) in which only aluminum potassium sulfate

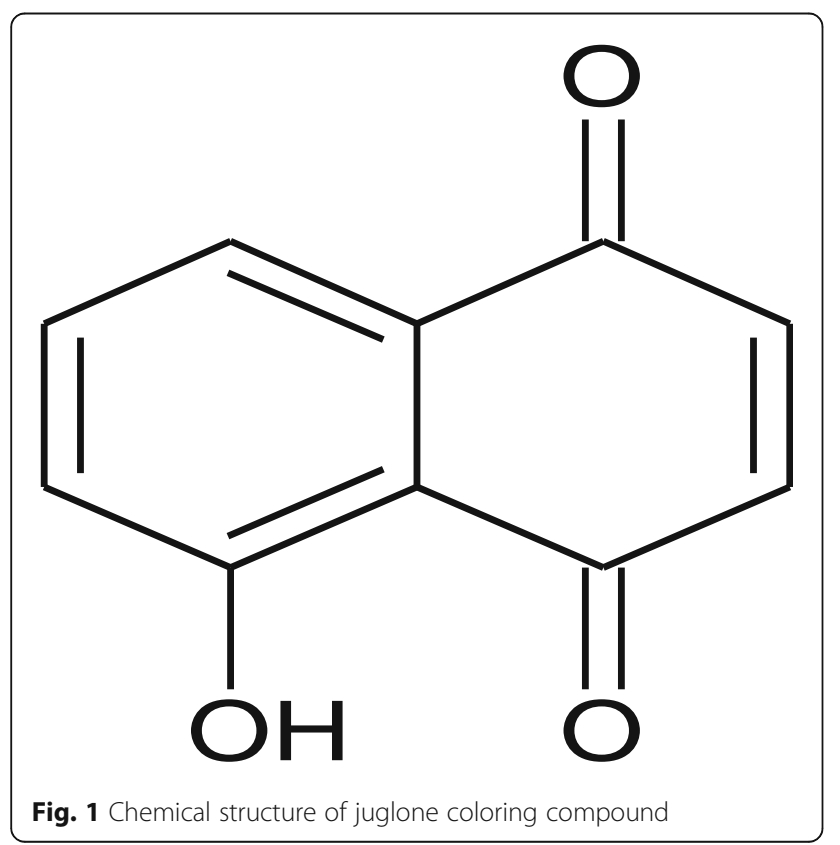

mordant is used to study its effect on dyeing and fastness properties of wool fibers dyed with walnut bark. The present work focuses on the change in colorimetric and fastness properties of wool fibers by the effect of aluminum potassium sulfate, ferrous sulfate, and stannous chloride mordants in developing a wide range of beautiful shades on wool.

\section{Experimental}

Materials

$100 \%$ pure New Zealand Semi worsted woolen yarn (60 counts) was purchased from MAMB Woolens Ltd. Bhadohi, S R Nagar Bhadohi (U.P.), India. Walnut bark powder was purchased from SAM Vegetable Colours Pvt. Ltd. India. Metallic mordants such as aluminum potassium sulfate $\left(\mathrm{Al}_{2} \mathrm{~K}_{2} \quad\left(\mathrm{SO}_{4}\right)_{4} \cdot 24 \mathrm{H}_{2} \mathrm{O}\right)$, ferrous sulfate $\left(\mathrm{FeSO}_{4} \cdot 7 \mathrm{H}_{2} \mathrm{O}\right)$, and stannous chloride $\left(\mathrm{SnCl}_{2} \cdot 2 \mathrm{H}_{2} \mathrm{O}\right)$. Hydrochloric acid $(\mathrm{HCl})$, sodium hydroxide pellets, and sodium carbonate anhydrous used were of laboratory grade.

\section{Methods}

Extraction of natural dye from walnut bark

The color component was extracted from powder of walnut bark using aqueous extraction. Powdered walnut bark was taken in an aqueous solution using M:L (material to liquor) ratio 1:60 and kept for $12 \mathrm{~h}$, then heated at $90{ }^{\circ} \mathrm{C}$ for $60 \mathrm{~min}$ with occasional stirring, cooled, and filtered. The remaining residue was again heated for two more times to get the maximum yield of colorant. The filtrate obtained was used for identification and dyeing of woolen yarns.

\section{Spectral studies}

The maximum absorbance wavelength $\left(\lambda_{\max }\right)$ of the extracted dye from walnut bark was evaluated in aqueous solution by using Perkin Elmer Lambda-40 double beam UV-visible spectrophotometer. The UV-visible spectrum was obtained in the visible region $200-700 \mathrm{~nm}$. Fourier transform infrared spectroscopy (FTIR) of samples was recorded on a Bruker Tensor 37 FT-IR spectrophotometer ranging from 4000 to $500 \mathrm{~cm}^{-1}$. Discs were prepared by cutting samples of both pre- and postmordanted dyed woolen yarn into fine pieces and grinded with $\mathrm{KBr}$, used as internal standard.

\section{Mild scouring of woolen yarn}

Before the application of mordants, woolen yarn samples were soaked in non-ionic detergent solution $(5 \mathrm{ml} / \mathrm{L})$ as pre-treatment to enhance surface wettability (Sun and Tang 2011). 


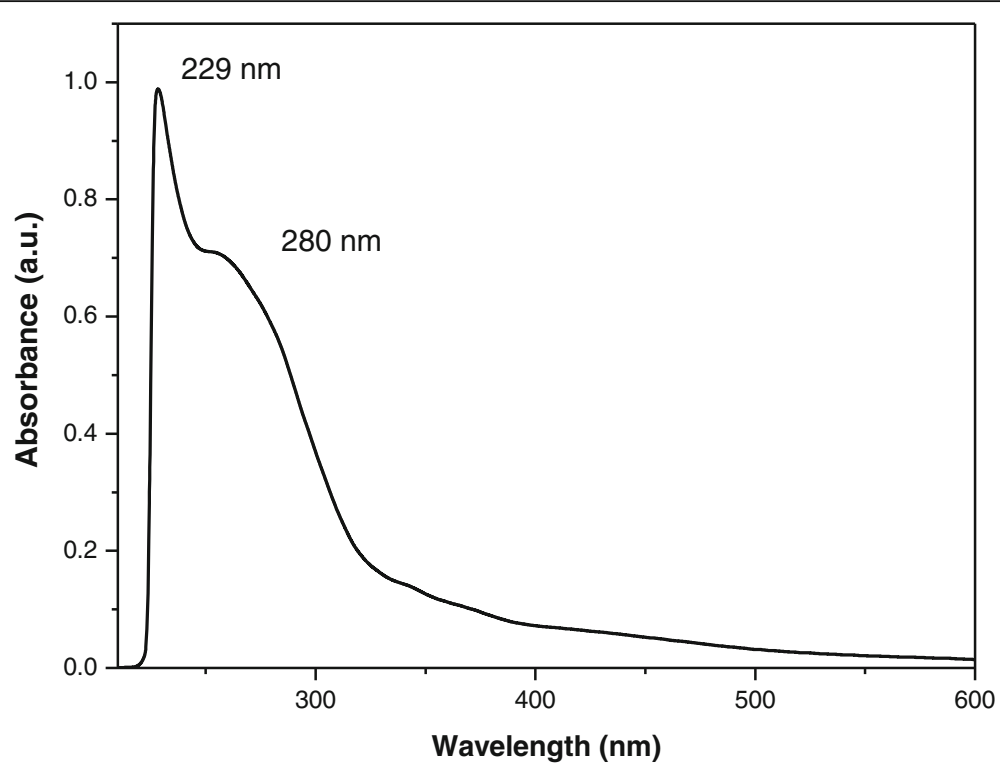

Fig. 2 UV visible spectra of Juglans regia L. bark extract

\section{Mordanting process}

Woolen yarn samples were mordanted by premordanting method using $10 \%$ aluminum potassium sulfate (o.w.f.), $5 \%$ ferrous sulfate (o.w.f) and 1\% stannous chloride (o.w.f.) (on the weight of fabric/yarn). Concentration of mordants was fixed as per our previous results (Shabbir et al. 2016). Mordants were dissolved in water and soaked woolen yarns samples were immersed in mordant solutions. The $\mathrm{pH}$ of mordant solution was kept at neutral and mordanting was done for $60 \mathrm{~min}$ with M:L of $1: 40$ at $90{ }^{\circ} \mathrm{C}$. Mordanted woolen yarn samples were rinsed with running tap water to remove superfluous (unused) mordants.

\section{Dyeing}

The dye stock solution was prepared by dissolving $76.5 \mathrm{~g}$ of walnut into 3 litres of water. The extracted dye solution was divided into different concentrations ranging between 1 and 20\% (o.w.f.). The dyeing experiments were performed using $\mathrm{M}$ : $\mathrm{L}$ ratio of 1:40 in separate baths with manual agitation at $\mathrm{pH} 7$ using 1, 5, 10, 15, and $20 \%$ (o.w.f.) dye concentrations. Woolen yarns were

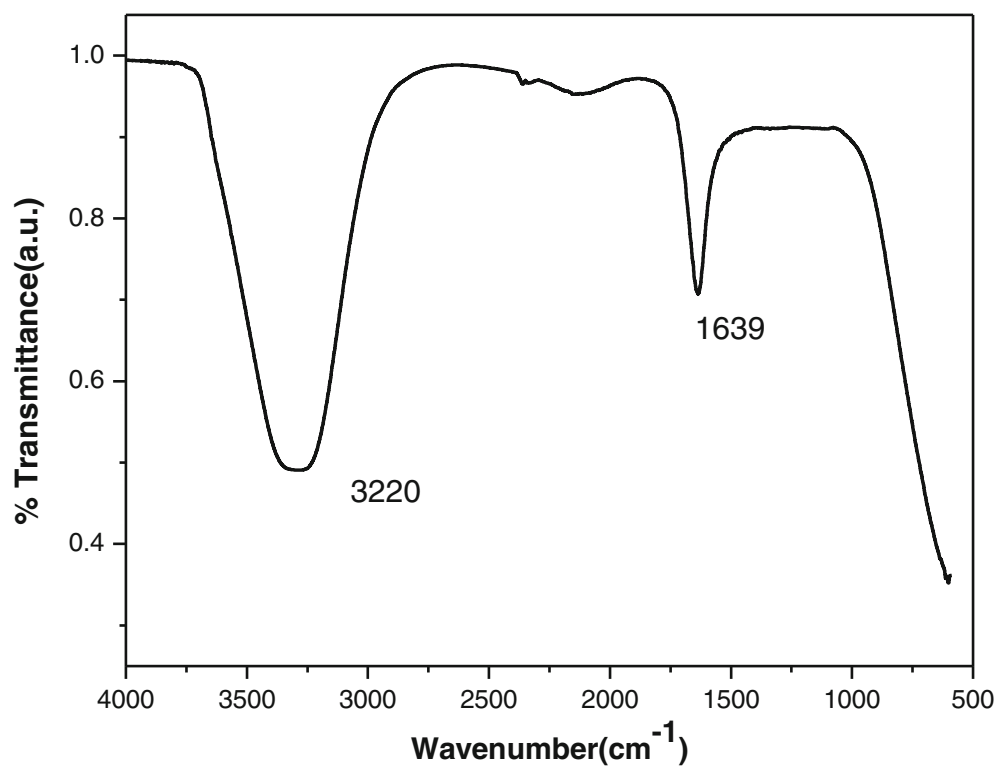

Fig. 3 FTIR spectra of Juglans regia L. bark extract 
Table 1 Colorimetric properties of unmordanted and mordanted dyed wool samples

\begin{tabular}{|c|c|c|c|c|}
\hline Mordant & $L^{*}$ & $a^{*}$ & $b^{*}$ & K/S \\
\hline \multicolumn{5}{|l|}{$1 \%$ walnut } \\
\hline Unmordanted & 62.46 & 3.04 & 11.27 & 1.12 \\
\hline $1 \% \mathrm{SnCl}_{2}$ & 65.13 & 2.45 & 12.3 & 1.38 \\
\hline $5 \% \mathrm{FeSO}_{4}$ & 54.97 & 2.82 & 4.88 & 2.17 \\
\hline $10 \%$ alum & 69.43 & 3.56 & 14.93 & 1.13 \\
\hline \multicolumn{5}{|l|}{$5 \%$ walnut } \\
\hline Unmordanted & 49.20 & 5.77 & 9.21 & 1.51 \\
\hline $1 \% \mathrm{SnCl}_{2}$ & 56.3 & 5.66 & 11.08 & 1.66 \\
\hline $5 \% \mathrm{FeSO}_{4}$ & 51.28 & 4.75 & 8.42 & 2.50 \\
\hline $10 \%$ alum & 58.3 & 6.17 & 12.24 & 1.51 \\
\hline \multicolumn{5}{|l|}{$10 \%$ walnut } \\
\hline Unmordanted & 50.71 & 7.09 & 10.59 & 2.60 \\
\hline $1 \% \mathrm{SnCl}_{2}$ & 43.61 & 8.44 & 11.83 & 4.23 \\
\hline $5 \% \mathrm{FeSO}_{4}$ & 64.25 & 6.60 & 16.42 & 5.80 \\
\hline $10 \%$ alum & 48.36 & 6.81 & 10.96 & 2.80 \\
\hline \multicolumn{5}{|l|}{$15 \%$ walnut } \\
\hline Unmordanted & 41.38 & 6.13 & 8.35 & 3.76 \\
\hline $1 \% \mathrm{SnCl}_{2}$ & 33.05 & 5.28 & 9.63 & 7.68 \\
\hline $5 \% \mathrm{FeSO}_{4}$ & 35.86 & 7.43 & 10.7 & 9.27 \\
\hline $10 \%$ alum & 41.48 & 5.68 & 9.61 & 4.22 \\
\hline \multicolumn{5}{|l|}{$20 \%$ walnut } \\
\hline Unmordanted & 41.12 & 5.86 & 7.73 & 4.27 \\
\hline $1 \% \mathrm{SnCl}_{2}$ & 34.97 & 7.54 & 10.48 & 7.95 \\
\hline $5 \% \mathrm{FeSO}_{4}$ & 27.50 & 4.98 & 6.92 & 11.51 \\
\hline $10 \%$ alum & 38.62 & 7.14 & 10.54 & 6.14 \\
\hline
\end{tabular}

*denotes CIE version drenched to dyeing baths containing warm dye solution. The dye bath temperatures were raised to simmering point $\left(91-93{ }^{\circ} \mathrm{C}\right)$ and at a rate of $2{ }^{\circ} \mathrm{C}$ per min and maintained at that level for $60 \mathrm{~min}$ (Rather et al. 2016a, b). Finally dyed samples were washed with $5 \mathrm{ml} / \mathrm{L}$ non-ionic detergent (Safewash Wipro), rinsed with running tap water, and dried in shade.

\section{Evaluation of color characteristics}

The CIELab $\left(\mathrm{L}^{*}, \mathrm{a}^{*}, \mathrm{~b}^{*}, \mathrm{C}^{*}, \mathrm{~h}^{\mathrm{o}}\right)$ and color strength $(\mathrm{K} / \mathrm{S})$ values of dyed and mordanted dyed samples were evaluated by using Gretag Macbeth Color-Eye 7000 A Spectrophotometer connected to a computer with installed software of MiniScan XE Plus. The color strength $(\mathrm{K} / \mathrm{S})$ in the visible region of the spectrum $(400-700 \mathrm{~nm})$ was calculated based on the Kubelka-Munk Eq. 1.

$$
\frac{K}{S}=\frac{(1-R)^{2}}{2 R}
$$

Where $K$ is absorption coefficient, $S$ is scattering coefficient, and $R$ is reflectance of dyed samples.

Chroma $\left(c^{*}\right)$ and hue angles $\left(h^{\circ}\right)$ were calculated using following equations:

$$
\begin{aligned}
& \text { Chroma }\left(c^{*}\right)=\sqrt{a^{2}+b^{2}} \\
& \text { Hue angle }\left(h^{\circ \circ}\right)=\tan ^{-1}(b / a)
\end{aligned}
$$

\section{Fastness testing}

The light fastness of dyed woolen yarn samples were conducted on digi light $\mathrm{Nx}^{\mathrm{TM}}$ having water cooled Mercury Blended Tungsten lamp as per test method AATCC 16E-

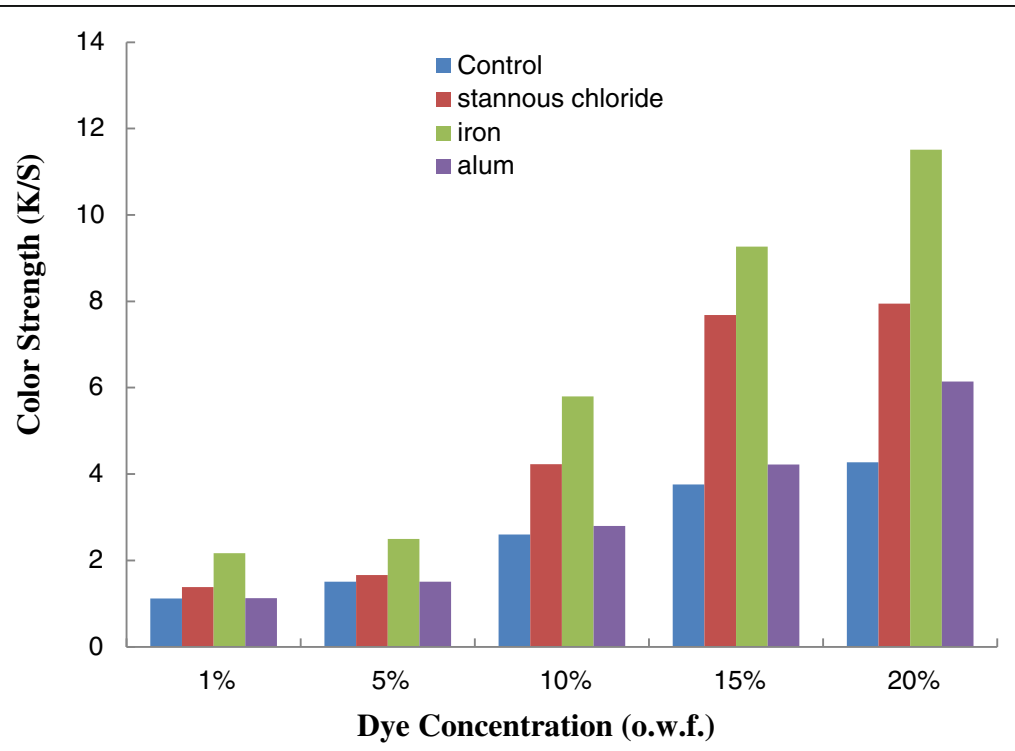

Fig. 4 Effect of mordants and dye concentrations on color strength (K/S) values dyed samples 


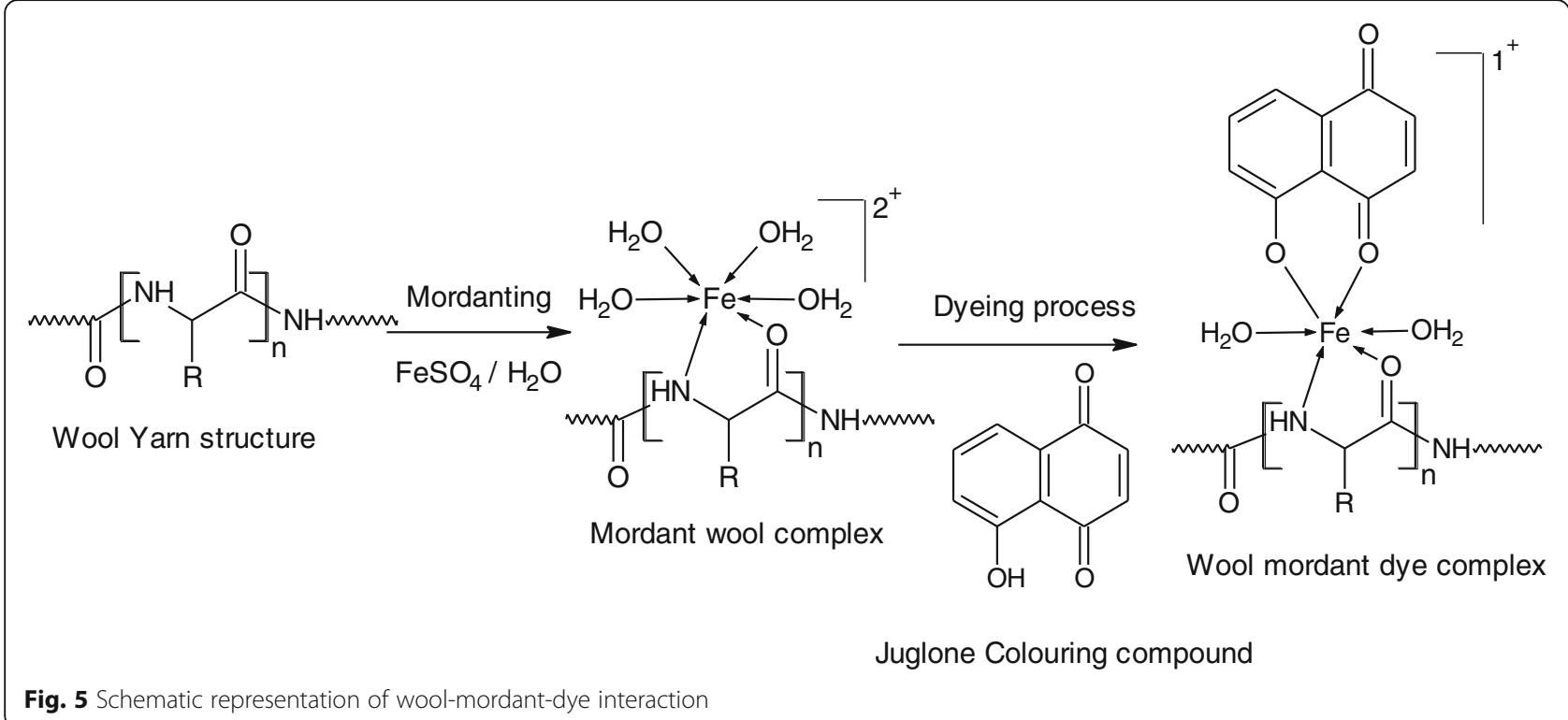

1993 (2004) similar to ISO 105-B02:1994 (Amd.2:2000). The wash fastness of dyed woolen yarn samples was measured in Launder-o-meter as per the ISO 105-C06:1994 (2010) specifications. Dry and wet rub fastness of the dyed woolen yarn samples were tested using a Crock-meter as per Indian standard IS 766:1988 (Reaffirmed 2004) based on ISO $105-\mathrm{X} 12: 2001$ by mounting the fabric on panel and giving ten strokes for dry and wet rub fastness tests. The samples were assessed for staining on white adjacent fabrics (wool and cotton).

\section{Results and discussion}

In the endeavor to explore novel adsorbent systems and to determine the extent of adsorption (efficiency of particular adsorbent), it is essential to establish the most appropriate adsorption equilibrium correlation, which is indispensable for reliable prediction of adsorption parameters (Rather et al. 2016; Srivastava et al. 2006). In the perspective of equilibrium relationships (adsorption isotherms), the interaction of adsorbents (dyes and mordants) with the adsorbent materials (wool fiber) is discussed and are critical for optimization of the adsorption mechanism pathways, expression of surface properties, efficiencies of adsorbents, and effective design of the adsorption systems (Rather et al. 2016; Gimbert et al. 2008). In the present study, the interaction between woolen yarn samples, mordants, and dye molecules was studied on the basis of enhanced color strength values $(\mathrm{K} / \mathrm{S})$ after mordanting and dyeing processes. Additionally, UV-Visible and FTIR spectral

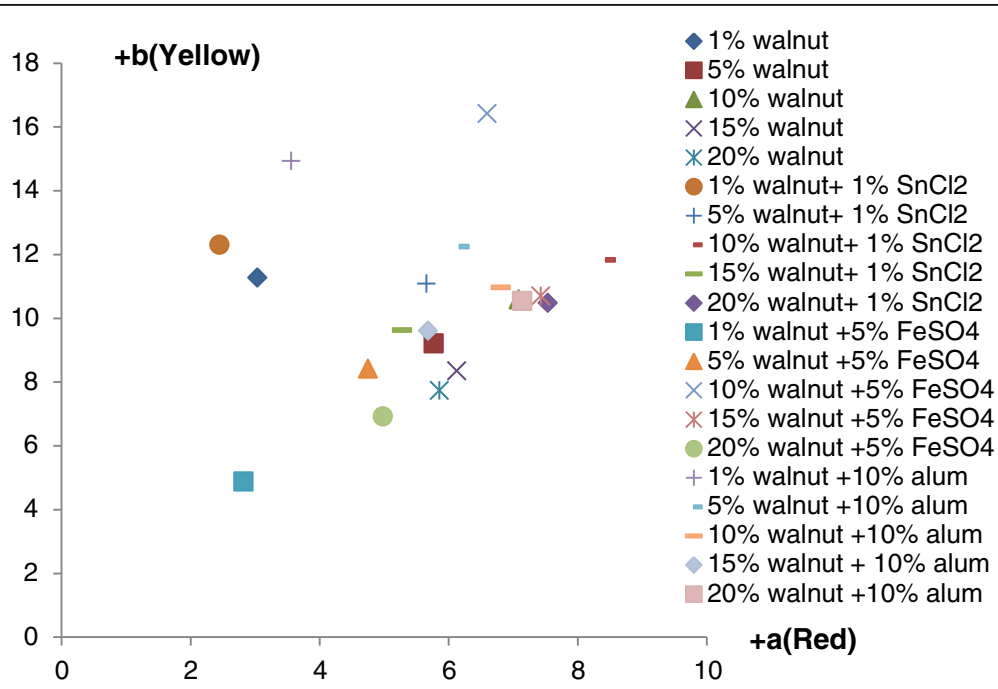

Fig. $6 a^{*}-b^{*}$ plot of unmordanted and mordanted dyed samples 


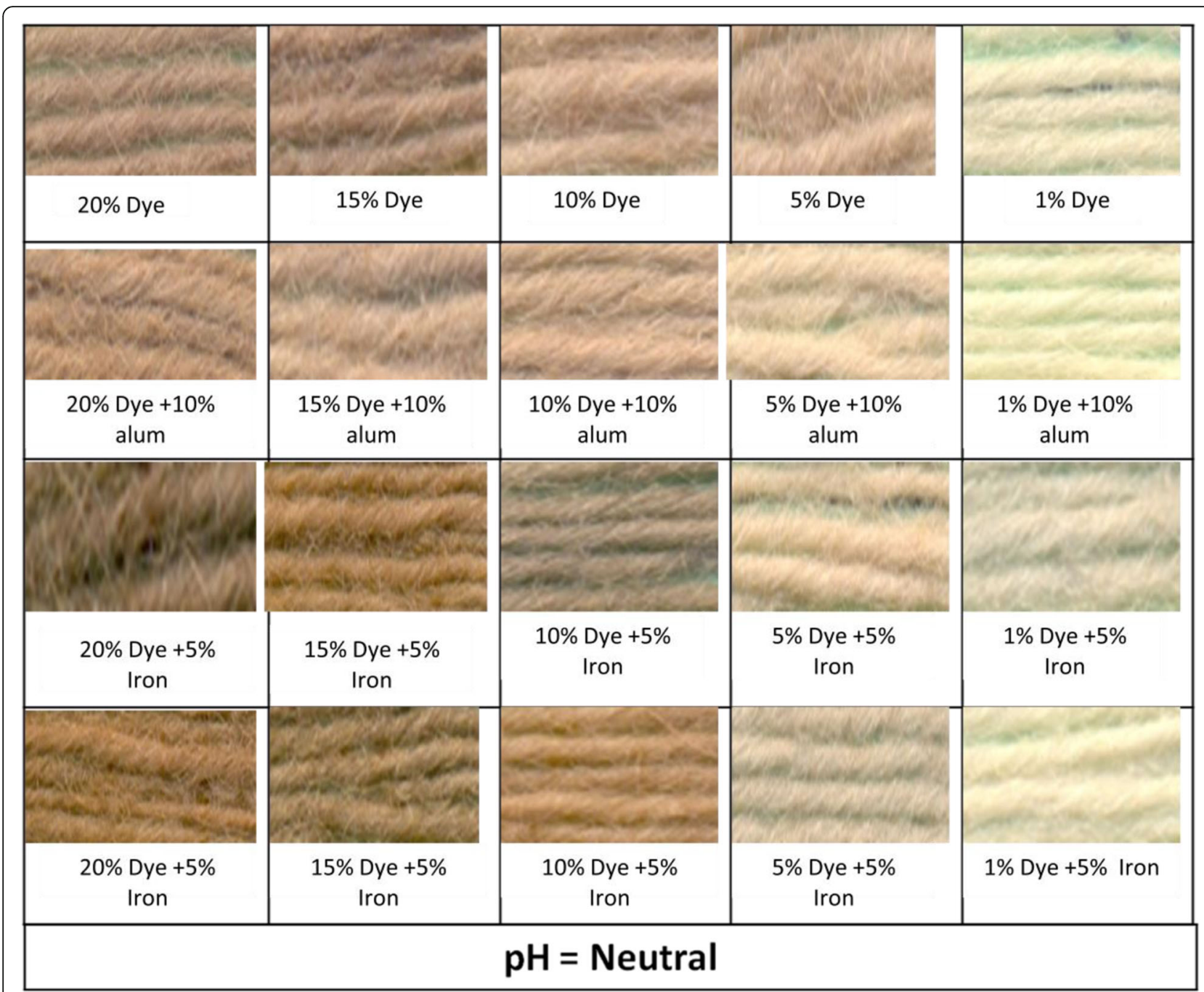

Fig. 7 Shade card of the dyed samples

analysis were used to identify the chromophoric groups present in dye molecules which are supposed to be the main contributors of enhanced chemical interactions (Rather et al. 2016a, b).

\section{UV absorption and FTIR spectral studies}

Absorption spectra of natural dyes depends upon the nature, number, and position of chromophore and auxochromic groups, as well as the type and polarity of the solvent used for analyzing absorption spectra (Oakes \& Dixon 2004). Figure 2 shows the UV spectra of extracted dye from J. regia L. Absorption spectra of $J$. regia dye shows two major bands in the region of $\lambda_{\max } 229$ and $280 \mathrm{~nm}$ which are ascribed to $\pi-\pi^{*}$ and $n-\pi^{*}$ transitions of carbonyl group, respectively (Cotton and Wilkinson 1972).

The FTIR spectra of $J$. regia dye displays two intense bands in the region of 3220 and $1639 \mathrm{~cm}^{-1}$, corresponding to hydrogen bonded $-\mathrm{OH}$ stretching and $-\mathrm{C}-\mathrm{O}$ stretching frequency (Fig. 3).

\section{Colorimetric properties}

The color strength $(\mathrm{K} / \mathrm{S})$ values and color parameters such as $\mathrm{L}^{*}, \mathrm{a}^{*}, \mathrm{~b}^{*}$ of unmordanted and mordanted woolen yarn dyed with walnut bark extracts are shown in Table 1. It is evident from the results that color strength $(\mathrm{K} / \mathrm{S})$ values increases with increase in concentration of walnut dye. In general, dyeing at low dye concentration resulted high $\mathrm{L}^{*}$ and low $\mathrm{a}^{*}$ values means brighter and less red color shade. This is attributed to concentration gradient of dye on fiber via adsorption. Increase in dye bath concentration leads more dye transfer to the fabric, and thus a higher apparent depth of color occurs (Rather et al. 2016). According to the results expressed in Fig. 4 and Table 1, the unmordanted 
Table 2 Fastness properties of unmordanted and mordanted dyed wool samples

\begin{tabular}{|c|c|c|c|c|c|c|}
\hline \multirow[t]{2}{*}{ Mordant } & \multirow{2}{*}{$\begin{array}{l}\text { Light } \\
\text { fastness }\end{array}$} & \multicolumn{3}{|c|}{ Wash fastness } & \multicolumn{2}{|c|}{ Rub fastness } \\
\hline & & $\overline{c . c}$ & c.s & $\overline{c . w}$ & Dry & Wet \\
\hline \multicolumn{7}{|l|}{$1 \%$ walnut } \\
\hline Unmordanted & 5 & $4-5$ & 5 & 5 & 4 & 4 \\
\hline $1 \% \mathrm{SnCl}_{2}$ & 5 & $4-5$ & 5 & 5 & $4-5$ & 4 \\
\hline $5 \% \mathrm{FeSO}_{4}$ & 5 & 4 & 5 & 5 & $4-5$ & $4-5$ \\
\hline $10 \%$ alum & 5 & $4-5$ & 5 & 5 & 4 & $4-5$ \\
\hline \multicolumn{7}{|l|}{$5 \%$ walnut } \\
\hline Unmordanted & 5 & 4 & 5 & 5 & $4-5$ & 4 \\
\hline $1 \% \mathrm{SnCl}_{2}$ & 5 & 4 & 5 & 5 & $4-5$ & 4 \\
\hline $5 \% \mathrm{FeSO}_{4}$ & 5 & 4 & 5 & 5 & 4 & $4-5$ \\
\hline $10 \%$ alum & 5 & 5 & $3-4$ & 5 & 5 & $3-4$ \\
\hline \multicolumn{7}{|l|}{$10 \%$ walnut } \\
\hline Unmordanted & 5 & 3 & 5 & 5 & $4-5$ & 3 \\
\hline $1 \% \mathrm{SnCl}_{2}$ & 5 & $3-4$ & 5 & 5 & 4 & 3 \\
\hline $5 \% \mathrm{FeSO}_{4}$ & 5 & $4-5$ & 5 & 5 & 4 & $3-4$ \\
\hline $10 \%$ alum & 5 & $4-5$ & 5 & 5 & $3-4$ & $3-4$ \\
\hline \multicolumn{7}{|l|}{$15 \%$ walnut } \\
\hline Unmordanted & 5 & 4 & 5 & 5 & $4-5$ & 3 \\
\hline $1 \% \mathrm{SnCl}_{2}$ & 5 & $3-4$ & 5 & 5 & 4 & $3-4$ \\
\hline $5 \% \mathrm{FeSO}_{4}$ & 5 & $4-5$ & 5 & 5 & 4 & $3-4$ \\
\hline $10 \%$ alum & 5 & 4 & 5 & 5 & $3-4$ & $3-4$ \\
\hline \multicolumn{7}{|l|}{$20 \%$ walnut } \\
\hline Unmordanted & 5 & $4-5$ & 5 & 5 & $4-5$ & 4 \\
\hline $1 \% \mathrm{SnCl}_{2}$ & 5 & 3 & 5 & 5 & $3-4$ & $3-4$ \\
\hline $5 \% \mathrm{FeSO}_{4}$ & 5 & $4-5$ & 5 & 5 & 4 & 4 \\
\hline $10 \%$ alum & 5 & $4-5$ & 5 & 5 & 3 & 3 \\
\hline
\end{tabular}

c.c. color change, c.s. color staining on cotton

c.w. color staining on wool

dyed woolen yarn showed lower dye uptake (low K/S values) compared with mordanted dyed woolen yarn (higher $\mathrm{K} / \mathrm{S}$ values). Mordanting increases interaction between woolen yarn functional groups (amine functionality) and dye functional groups (hydroxyl and carbonyl groups), resulting in increased dye exhaustion values which can be directly correlated with increase color strength values of dyed woolen yarn samples (Rather et al. 2016a, b). The proposed schematic representation of increased interaction between dye and woolen yarn through mordanting process (Ferrous sulfate mordanting) is shown in Fig. 5.

Among the mordanted samples, ferrous sulfate treated samples shows higher color strength values than alum and stannous chloride mordanted samples, results in darker shades in ferrous sulfate mordanted samples. The activity sequence in terms of increasing color strength values follows the order ferrous sulfate $>$ stannous chloride $>$ alum $>$ unmordanted woolen yarn samples. This is ascribed to strong coordinate complex formation tendency of ferrous sulfate within the fiber (Fig. 5) (Bhattacharya and Shah 2000).

From the experimental results of $\mathrm{a}^{*}-\mathrm{b}^{*}$ plot (Table 1, Fig. 6), it is clearly indicated that color coordinates of all dyed samples (control and mordanted) lie in the redyellow quadrant of CIEL*a*b* color space diagram. Use of metal salts significantly altered the colorimetric data owing to their complexation and interaction developed with woolen yarn. Alum mordant shifts color coordinates more towards yellow region, where as ferrous sulfate mordant shifts color coordinates more towards red region of color space diagram. However, the effect of stannous chloride mordant was found highly diversified with the change in dye concentration, although bright yellow shades were obtained. On the basis of the color strength $(\mathrm{K} / \mathrm{S})$ values and CIEL"a*b* parameters, it can be concluded that walnut dye with or without mordants can be successfully used as natural colorant for developing variety of shades of different hue and tone (Fig. 7).

\section{Color fastness}

The color fastness characteristics (light, wash and rub) of all mordanted and unmordanted dyed woolen yarn samples are given in Table 2. It is from the color fastness tests that all samples show very good light fastness ratings of 5 on blue scale. Mordanting has been found to have no effect on light fastness ratings of dyed samples.

The wash fastness results of all samples were found to be in the range of fairly good to good ratings of 3-5. Mordanting with different metal salts has significantly altered wash fastness ratings of dyed woolen yarn. Alum and ferrous sulfate positively affected the color change in wash fastness results but tin mordants reduce the rating up to 3. Fastness results are also proving the better complexation of iron mordant with wool fiber and dye molecules. The color change in dyed wool of all samples was found to be from fairly good to good level rating of $3-4$, whereas the color staining on wool and cotton was found to be very good rating of 5 . Color fastness to crocking was found to be within the range of 3-5 means fairly good to good level in all dyed yarn samples. Woolen yarn samples dyed with low concentration showed better wash and rub fastness properties. This is attributed to the fact that at higher dye concentration there is leeching of color from dyed wool samples due to physical adsorption. The results of present study are in good correlation with previously reported work by Ali et al. (2016).

\section{Conclusion}

Woolen yarn samples were dyed with a natural coloring agent extracted from walnut bark in order to develop 
natural shades in conjunction with small amounts of different metallic salt mordants. Novel and fashionable shades of light and bright brown shades were observed in alum mordanted dyed samples; reddish brown shades in stannous chloride mordanted samples, and dark brown shades in ferrous sulfate mordanted samples (Fig. 7). The maximum relative color strength followed the trend as ferrous sulfate mordanted $>$ stannous chloride $>$ alum $>$ unmordanted. All the dyed woolen yarn samples irrespective of metal mordants showed good to very good light fastness ratings. The wash fastness property was found to be from fairly good to excellent level in most of the cases whereas rub fastness was observed from fairly good to good level in most of cases. Based on the results of colorimetric evaluation as well as fastness properties, it can be concluded that dye obtained from $J$. regia $\mathrm{L}$. bark has promising future in textile dyeing industry.

\section{Acknowledgements}

Financial support provided by University Grants Commission, Govt. of India; through Central University Fellowship for Mohd Nadeen Bukhari and BSR Fellowship for Meritorious Students for Mohd Shabbir and Luqman Jameel Rather, are highly acknowledged.

\section{Authors' contributions}

MNB carried out the dyeing studies. SI interpreted experimental data and drafted the manuscript. MS and LJR helped in carrying out experiments. MS and MAK helped in characterizations. US helped in designing of shade cards. FM designed the experimental protocol along with MNB. All authors read and approved the final manuscript.

\section{Competing interests}

The authors declare that they have no competing interests.

\section{Author details}

'Department of Chemistry, Jamia Millia Islamia, New Delhi 110025, India. ${ }^{2}$ Department of Post Harvest Engineering and Technology, Faculty of Agricultural Sciences, A.M.U, Aligarh 202002, U.P, India.

Received: 4 November 2016 Accepted: 29 December 2016 Published online: 17 January 2017

\section{References}

Ali, M. A., Almahy, H. A., \& Band, A. A. A. (2013). Extraction of carotenoids as natural dyes from the Daucus carota Linn (carrot) using ultrasound in Kingdom of Saudi Arabia. Research Journal of Chemical Sciences, 31, 63-66.

Ali, M. K., Islam, S., \& Mohammad, F. (2016). Extraction of natural dye from walnut bark and its dyeing properties on wool yarn. Journal of Natural Fibers, 13, 458-469.

Bechtold, T., Turcanu, A., Ganglberger, E., \& Geissler, S. (2003). Natural dyes in modern textile dye house-how to combine experiences of two centuries to meet demands of the future? Journal of Cleaner Production, 11, 499-509.

Bhattacharya, S. D., \& Shah, A. K. (2000). Metal ion effect on dyeing of wool fabric with catechu. Coloration Technology, 116, 10-12.

Chopra, R. N., Nayar, S. L., \& Chopra, R. C. (1996). Glossary of Indian medicinal plants (Including the Supplement) (p. 11). New Delhi: Council of Scientific and Industrial Research.

Cotton, F. A., \& Wilkinson, G. (1972). Advanced inorganic chemistry: a comprehensive text (3rd ed.). New York: Wiley.

Cristea, D., \& Vilarem, G. (2006). Improving light fastness of natural dyes on cotton yarn. Dyes and Pigments, 70, 238-245.

El-Nagar, K., Sanad, S. H., Mohamed, A. S., \& Ramadan, A. (2005). Mechanical properties and stability to light exposure for dyed Egyptian cotton fabric with natural and synthetic dyes. Polymer-Plastics Technology and Engineering, 44, 1269-1279.
Gimbert, F., Morin-Crini, N., Renault, F., Badot, P. M., \& Crini, G. (2008). Adsorption isotherm models for dye removal by cationized starch-based material in a single component system: Error analysis. Journal of Hazardous Materials, 157, 34-46.

Grifoni, D., Bacci, L., Zipoli, G., Carreras, G., Baronti, S., \& Sabatini, F. (2009). Laboratory and outdoor assessment of UV protection offered by Flax and Hemp fabrics dyed with natural dyes. Photochemistry and Photobiology, 85, 313-320.

Hwang, J. S., \& Park, S. Y. (2013). Application of green husk of Juglans regia Linn and effect of mordants for staining of silk. Journal of Convergence In Technology (JCIT), 12, 279-283.

Hwang, E. K., Kim, M. S., Lee, D. S., \& Kim, K. B. (1998). Colour development of natural dyes with some mordants. Journal of Korean Fibre Society, 35, 490-497.

Islam, S., \& Mohammad, F. (2014). Emerging green technologies and environment friendly products for sustainable textiles. In S. S. Muthu (Ed.), Roadmap to sustainable textiles and clothing (pp. 63-82). Singapore: Springer.

Islam, S., Rather, L. J., Shahid, M., Khan, M. A., \& Mohammad, F. (2014). Study the effect of ammonia post-treatment on color characteristics of annatto-dyed textile substrate using reflectance spectrophotometery. Industrial Crops and Products, 59, 337-342.

Jothi, D. (2008). Extraction of natural dyes from African marigold flowers (Tagetes erecta) for textile coloration. Autex Research Journal, 8, 49-53.

Khan, M. A., Khan, M., Srivastava, P. K., \& Mohammad, F. (2006). Extraction of natural dyes from cutch, ratanjot and madder, and their application on wool. Colourage, 53, 61-68.

Khan, S. A., Ahmad, A., Khan, M. I., Yusuf, M., Shahid, M., Manzoor, N., \& Mohammad, F. (2012). Antimicrobial activity of wool yarn dyed with Rheum emodi L. (Indian Rhubarb). Dyes and Pigments, 95, 206-214.

Lee, Y. H., \& Kim, H. D. (2004). Dyeing properties and colour fastness of cotton and silk fabrics dyed with Cassia tora L. extract. Fibers and Polymers, 5, 303-308.

Lee, Y., Hwang, E., \& Kim, H. (2009). Colorimetric assay and antibacterial activity of cotton, silk and wool fabrics dyed with peony, pomegranate, clove, Coptis chinenis and gallnut extracts. Materials, 2, 10-21.

Micheal, M. N., Tera, F. M., \& Aboelanwar, S. A. (2003). Colour measurements and colourant estimation of natural red dyes on natural fabrics using different mordants. Colourage, 1, 31-42.

Mirjalili, M., \& Karimi, L. (2013). Extraction and characterization of natural dye from green walnut shells and its use in dyeing polyamide: focus on antibacterial properties. Journal of Chemistry, 0, 1-9.

Mirjalili, M., Nazarpoor, K. \& Karimi, L. (2011). Extraction and identification of dye from walnut green husks for silk dyeing. Asian Journal of Chemistry, 23, 1055-1059.

Oakes, J., \& Dixon, S. (2004). Physical interactions of dyes in solution - influence of dye structure on aggregation and binding to surfactants J polymers. Review of Progress in Coloration Technology, 34, 110.

Rather, L. J., Islam, S., \& Mohammad, F. (2015). Study on the application of Acacia nilotica natural dye to wool using fluorescence and FT-IR spectroscopy. Fibers and Polymers, 16, 1497-1505.

Rather, L. J., Islam, S., Azam, M., Shabbir, M., Bukhari, M. N., Shahid, M., Khan, M. A., Haque, Q. M. R., \& Mohammad, F. (2016). Antimicrobial and fluorescence finishing of woolen yarn with Terminalia arjuna natural dye as an ecofriendly substitute to synthetic Antibacterial agents. RSC Advances, 6, 39080-39094.

Rather, L. J., Islam, S., Khan, M. A., \& Mohammad, F. (2016). Adsorption and kinetic studies of Adhatoda vasica natural dye onto woolen yarn with evaluations of colorimetric and fluorescence characteristics. Journal of Environmental Chemical Engineering, 4, 1780-1796.

Rather, L. J., Islam, S., Shabbir, M., Bukhari, M. N., Shahid, M., Khan, M. A., \& Mohammad, F. (2016). Ecological dyeing of woolen yarn with Adhatoda vasica natural dye in the presence of biomordants as an alternative copartner to metal mordants. Journal of Environmental Chemical Engineering, 4, 3041-3049.

Samanta, A. K., \& Agarwal, P. (2009). Application of natural dyes on textiles. Indian Journal of Fibre and Textile Research, 34, 384-399.

Shabbir, M., Islam, S., Bukhari, M. N., Rather, L. J., Khan, M. A., \& Mohammad, F. (2016). Application of Terminalia chebula natural dye on wool fiber-evaluation of color and fastness properties. Textiles and Clothing Sustainability, 2, 1-9.

Shahid, M., Ahmad, A., Yusuf, M., Khan, M. I., Khan, S. A., Manzoor, N., \& Mohammad, F. (2012). Dyeing, fastness and antimicrobial properties of woolen yarns dyed with gallnut (Quercus infectoria Oliv.) extract. Dyes and Pigments, 95, 53-61.

Shahid, M., Islam, S., \& Mohammad, F. (2013). Recent advancements in natural dye applications: a review. Journal of Cleaner Production, 53, 310-331.

Shaukat, A., Tanveer, H., \& Rakhshanda, N. (2009). Optimization of alkaline extraction of natural dye from Henna leaves and its dyeing on cotton by exhaust method. Journal of Cleaner Production, 17, 61-66. 
Siva, R. (2007). Review article. Status of natural dyes and dye-yielding plants in India. Current Science, 92, 916-925.

Srivastava, V. V., Swamy, M. M., Mall, I. D., Prasad, B., \& Mishra, I. M. (2006). Adsorptive removal of phenol by bagasse fly ash and activated carbon: equilibrium, kinetics and thermodynamics. Colloids Surface A, 272, 89-104.

Sun, S. S., \& Tang, R. C. (2011). Adsorption and UV protection properties of the extract from honeysuckle onto wool. Industrial \& Engineering Chemistry Research, 50, 4217-4224.

Tsamouris, G., Hatziantoniou, S., \& Demetzos, C. (2002). Lipid analysis of Greek walnut oil (Juglans regia L.). Zeitschrift fur Naturforschung. C. Journal of Biosciences (Z Naturforsch C Biosci), 57, 51-60.

Tutak, M., \& Benli, H. (2011). Colour and fastness of fabrics dyed with walnut (Juglans regia L.) Base natural dyes. Asian Journal of Chemistry, 23, 566-568.

Vankar, P. S., Rakhi, S., \& Verma, A. (2007). Enzymatic natural dyeing of cotton and silk fabrics without metal mordants. Journal of Cleaner Production, 15, 1441-1450.

Yusuf, M., Shahid, M., Khan, M. I., Khan, S. A., Khan, M. A., \& Mohammad, F. (2015). Dyeing studies with henna and madder: a research on effect of tin (II) chloride mordant. Journal of Saudi Chemical Society, 19, 64-72.

\section{Submit your manuscript to a SpringerOpen ${ }^{\circ}$ journal and benefit from:}

- Convenient online submission

- Rigorous peer review

- Immediate publication on acceptance

- Open access: articles freely available online

- High visibility within the field

- Retaining the copyright to your article

Submit your next manuscript at $\boldsymbol{s p r i n g e r o p e n . c o m ~}$ 